\title{
EMPREENDEDORISMO CRIATIVO: \\ A PRESERVAÇÃO DA PRIVACIDADE E A COLETA DE DADOS NO COMÉRCIO ELETRÔNICO ${ }^{1}$
}

\author{
Creative entrepreneurship: the preservation of privacy \\ and data collection in electronic commerce
Emprendedorismo creativo: la conservación de privacidad y recopilación de datos en el comercio electrónico

\author{
Bibiana Silveira-Nunes \\ Universidade Feevale \\ bibianasilveira@gmail.com
Leonardo Brunetti Macedo
Universidade Feevale
leonardomb@gmail.com
Sandra Portella Montardo
Universidade Feevale
sandramontardo@feevale.br

\section{Resumo}

Investigamos a preservação da privacidade na internet, especificamente em relação aos dados coletados pelos empreendedores criativos no comércio on-line. É nosso objetivo principal investigar se e como o empreendedor criativo protege a privacidade de seus consumidores no que cabe aos dados coletados para a formalização de negócios no comércio eletrônico. Como resultado entendemos que muitos empreendedores, apesar de se dizerem conhecedores da legislação, ainda não adequaram seus negócios on-line às disposições do Marco Civil da Internet, descumprindo os requisitos necessários para que uma de suas atividades-meio - a coleta de dados pessoais do potencial consumidor - observe as normas jurídicas relativas à proteção da privacidade e ao direito fundamental à informação que têm os consumidores.

Palavras-chave: Marco Civil da Internet. Empreendedorismo criativo. Privacidade.

\footnotetext{
${ }^{1} \mathrm{O}$ artigo é produto de investigação em curso ligada ao Mestrado Profissional em Indústria Criativa - Feevale, que busca conceituar o empreendedorismo criativo como este emerge no mercado nacional, sendo que o termo denomina ações empreendedoras realizadas na intersecção entre Indústria Criativa e plataformas digitais. Utilizamos a terminologia "empreendedorismo criativo" por ser ela adotada pelos atores envolvidos em sua prática.
} 


\begin{abstract}
We investigate the preservation of privacy on the internet, specifically in relation to the data collected by creative entrepreneurs in on-line commerce. It is our primary goal to investigate whether and how the creative entrepreneur protects the privacy of its consumers as it relates to the data collected for the formalization of business in e-commerce. Thus, we understand that many entrepreneurs, despite being knowledgeable about the legislation, have not yet adapted their on-line business to the provisions of the Brazilian Civil Rights Framework for the Internet, failing to meet the requirements for one of their main activities - the gathering of potential consumers' personal data - in face of the legal rules relating to the protection of privacy and consumers' fundamental right to information.
\end{abstract}

Key words: Brazilian Civil Rights Framework. Creative entrepreneurship.Privacy.

\title{
Resumen
}

Investigamos la preservación de la privacidad en Internet, específicamente en los datos colectados por los emprendedores creativos en el comercio on-line. Es objetivo principal investigar si y como el emprendedor creativo protege la privacidad de sus consumidores en lo que respecta los datos recopilados para una formalización de negocios en comercio electrónico. Como resultado entendemos que muchos emprendedores, a pesar de que se conozcan las normativas básicas de la legislatura, no se han adaptado sus negocios on-line al Marco Civil de Internet, incumpliendo los requerimientos básicos para que una de sus actividades-medio - la coleta de datos personales de su consumidor en potencial - observe las normas jurídicas ligadas a la protección de la privacidad y al derecho fundamental de los consumidores a información.

Palabras clave: Marco Civil de Internet. Emprendedorismo creativo. Privacidad.

\section{INTRODUÇÃO}

Iniciar qualquer negócio exige o domínio de várias informações para que o empreendimento seja um verdadeiro sucesso: tarefa árdua no Brasil. Além de conhecimento técnico necessário para produzir determinado bem que será exposto à venda, ou do serviço que se disporá a prestar, o empreendedor deve estar atento às normas tributárias, regulamentos municipais de atividades e, dentre tantas outras regras, normas sobre o tratamento dos dados dos consumidores sempre que o negócio se der on-line.

A atuação comercial on-line cresce a índices vertiginosos. A previsão, a nível mundial, para 2016 foi de que vendas on-line alcançassem a marca de US\$1.92 trilhões; a projeção para 2018 é de que esse número atinja US\$2.356 trilhões (STATISTA.COM, 2017). Durante 2015, o faturamento brasileiro em e-commerce alcançou $\mathrm{R} \$ 41.3$ bilhões, com expectativa de alcançar R \$44.6 milhões (MOREIRA, 2016). Dados mostram que o faturamento no Brasil, 
durante o primeiro trimestre de 2016, chegou a $\mathrm{R} \$ 9.75$ bilhões (PROFISSIONALDEECOMMERCE.COM.BR, 2017). Dos profissionais que atuam neste ambiente, uma parte está formada por empreendedores criativos ${ }^{2}$, cujos produtos, tangíveis ou intangíveis, têm consumo de caráter principalmente simbólico, podendo acarretar troca monetária ou não. São estes produtos - que podem ser produtos físicos e digitais, serviços e até cursos e treinamentos dos mais variados - idealizados e produzidos pelos empreendedores, a partir de seus conhecimentos e criatividade individuais, excluindo-se aqui e-commerces de caráter de revenda.

Para perfectibilizar relações de consumo na internet, o empreendedor deve conhecer as regras jurídicas que tratam da principal atividade-meio de qualquer empreendimento on-line: a coleta de dados dos clientes. Por conta disso, mostra-se da maior importância saber se os empreendedores criativos estão atentos às principais regras do Marco Civil da Internet (MCI), especialmente no que tange à inviolabilidade da privacidade alheia e à coleta de dados.

Muito se discute acerca dos limites dessa atividade: a coleta de dados pessoais na internet. Por isso, é imprescindível esclarecer o que envolve essa prática, bem como o que são dados pessoais e se os empreendedores têm conhecimento das regras que cercam o tratamento de informações na internet. O que nos leva à seguinte questão de pesquisa: O Empreendedor Criativo respeita a privacidade dos consumidores em relação aos dados coletados durante as transações mediadas por plataformas on-line?

Assim, é nosso objetivo entender como o Empreendedor Criativo atuante no Brasil trata a questão da privacidade de dados coletados em suas interações com consumidores quando essas são mediadas por plataformas on-line. Considerando o MCI, e trocas monetárias mediadas pela internet, acreditamos ser relevante o estudo dos processos em curso, para verificação da postura do empreendedor criativo no mercado on-line: se ele conhece e respeita os limites legais para não violar a privacidade do seu consumidor. É nosso objetivo investigar se e como o empreendedor criativo protege a privacidade de seus consumidores no que cabe aos dados coletados para a formalização de negócios no comércio eletrônico. Objetivamos também 1) especificar os conceitos de privacidade e de coleta de dados;2) esclarecer quais dispositivos legais tratam do assunto e os métodos mais usuais de coleta de dados; e 3)

\footnotetext{
${ }^{2} \mathrm{O}$ tema "empreendedorismo criativo" é objeto de investigação em curso, por um dos pesquisadores, no Mestrado Profissional em Indústria Criativa. A pesquisa busca conceituar o fenômeno que emerge com o desenvolvimento do empreendedorismo em sua intersecção com Economia e Indústria Criativa e plataformas digitais (PARKER; VAN ALSTYNE; CHOUDARY, 2016). O conceito é retomado a frente.
} 
investigar como o empreendedor criativo se posiciona em relação à legislação no tocante à coleta de dados.

Para tanto, realizamos pesquisa descritiva de natureza qualitativa, com levantamento amostral realizado por meio de formulário on-line, distribuído por sites de redes sociais. Realizamos breve revisão de literatura sobre temas pertinentes, a saber, empreendedorismo criativo e limites da coleta de dados on-line. A seguir, descrevemos a metodologia e resultados, e concluímos com discussão de resultados e possíveis questões a serem exploradas sobre o tema.

\section{Empreendedorismo Criativo}

Por ser a discussão sobre o empreendedorismo que surge na intersecção entre Indústria Criativa, empreendedorismo criativo e plataformas digitais recente, não existe conceituação definitiva a respeito. Propomos aqui um cercamento teórico ao tema, construto que buscaremos definir por meio de pesquisa empírica. Por ora e baseados nas observações e sínteses realizadas até o momento, definimos o empreendedorismo criativo ao qual nos referimos como a atividade empreendedora que se dá no universo da Indústria Criativa por meio de mercados em redes sociais (POTTS et al., 2008), cujas ações são mediadas por plataformas digitais (PARKER; VAN ALSTYNE; CHOUDARY, 2016).

Poucas publicações diretamente definem Empreendedorismo Criativo. Estas estão limitadas a sites, sendo que abordamos aqui apenas duas, de publicação internacional e qualificadas por associação a órgãos legitimadores. Para o British Council Poland (2017), referência em Economia Criativa, esse empreendedor pode ser definido como indivíduo trabalhando no setor criativo que tenha: 1) demonstrado sucesso nos negócios nos termos clássicos de crescimento de negócios, e/ou em termos de sua reputação entre seus pares; 2) desenvolvido um empreendimento social ou sem fins lucrativos bem sucedido em termos de impacto e alcance; 3) mostrado liderança na indústria ao promover seu desenvolvimento em seu país; 4) desenvolvido iniciativas que desenvolvem e crescem o mercado para este setor em seu país (BRITISH COUNCIL POLAND, 2017, tradução nossa).

Apontam como qualidades de um Empreendedor Criativo 1) habilidade empreendedora; 2) capacidade de inovação no desenvolvimento de novos modelos de negócio; 3) habilidade de liderança, seu potencial para modificar o setor de atuação; 4) consciência e conhecimento do mercado; e 5) perspectivas internacionais e capacidade de criar redes de contatos em nível de Reino Unido e internacional (BRITISH COUNCIL 
POLAND, 2017). Como habilidade empreendedora, enfatizam a capacidade de avaliar e enfrentar riscos, habilidades corporativas e interpessoais. Bastante ênfase é dada para a auto iniciativa e capacidade de liderança, assim como conhecimento de mercado e networking. Estas características vão de encontro às características do empreendedor tradicional (BIRLEY; MUZYKA, 2001; DORNELAS; SPINELLI; ADAMS, 2014), com exceção da paixão por seu setor criativo, que vai ao encontro do discurso colocado por Howkins (2012), que enfatiza a palavra "paixão" quando falando na atuação empreendedora na Economia Criativa.

Recentemente, foi lançado o site Creative Entrepreneurs (2017), plataforma de referências para empreendedores nos setores artísticos. $\mathrm{O}$ site, parte de iniciativa do governo britânico para fomento do Empreendedorismo Criativo (SNOW, 2017), define o Empreendedor Criativo a partir da perspectiva do DCMS (2008), ligada à produção de propriedade intelectual, sendo o Empreendedor Criativo definido como 1) o fundador de uma empresa lucrativa cuja produção é o produto único da imaginação humana, também conhecida como propriedade intelectual; e 2) uma pessoa que cria um negócio rentável de nos trazer alegria, iluminação, beleza, uma jornada através da gama de emoções humanas e outras coisas, algoritmos e robôs não podem fazer (CREATIVE ENTREPRENEURS, 2017).

A plataforma (2017) continua sua definição de Empreendedorismo Criativo com um manifesto publicado no site Creativeentrepreneurs.co.uk (CREATIVE ENTREPRENEURS, 2017), seguindo a linha de Howkins (2012) no que tange à paixão pela carreira e setor de atuação. O texto, que delimita características específicas do Empreendedor Criativo, coloca este como diferente do empreendedor tradicional principalmente por sua escolha por um estilo de vida divergente, que preza por satisfação pessoal em detrimento de lucro financeiro.

Tais definições ajudam a salientar o fato de que, diferente do empreendedorismo clássico onde o sucesso do negócio é balizado pelos termos clássicos no crescimento de negócios - especificamente capital econômico -, no empreendedorismo criativo os capitais social, cultural e simbólico (BOURDIEU, 2007) são, não apenas indicadores de sucesso do negócio, mas também fator de produção do ativo criativo e de atribuição de valor por parte do consumidor.

Quanto à escolha pelo empreendedorismo por parte de criativos, estudos apontam que tal escolha está fortemente associada ao estilo de vida proposto e possibilitado pela ação empreendedora, sendo motivado predominantemente por escolhas pessoais por: a) auto emprego; b) equilíbrio entre trabalho e vida; c) controle do próprio tempo; d) habitação fora 
de grandes centros; e) busca por qualidade de vida (CHASTON, 208; MCCARTHY, 2008; PETERS et al., 2009; EIKHOF; HAUNSCHILD, 2006). A escolha por habitação fora de grandes centros ressoa com as colocações de Castells (2016) sobre o impacto de TICs no novo espaço industrial. Partimos, então, da hipótese de que a atuação no âmbito do Empreendedorismo Criativo está pautada pela escolha por um estilo de vida criativo.

Em mapeamento sistemático da produção científica acerca do tema empreendedorismo criativo indexado na base de dados SCOPUS, procuramos 1) validar hipótese de aumento no volume de estudos relacionados; 2) realizar retrato do movimento de publicações na área; 3) validar necessidade de pesquisas aprofundadas acerca do tema; e 4) identificar melhor terminologia para referência ao tema na busca por publicações qualificadas. A análise destes aponta para 167 documentos produzidos entre 1989 e 2015, sendo que há um aumento considerável na produção a partir do ano 2009. Tais resultados refletem não apenas o crescimento da produção científica sobre Indústria Criativa (PINHEIRO et al., 2015), mas também da produção sobre o tema Empreendedorismo Criativo.

Do ponto de vista quantitativo, os resultados apontam como melhor nomenclatura para referência ao tema "Empreendedorismo na Indústria Criativa". A predominância das áreas Negócios, Administração e Contabilidade e Ciências Sociais confirma o lugar de proeminência dos campos Administração e Comunicação nos estudos relacionados ao tema (PINHEIRO et al., 2015). Também, validamos a relevância de futuros estudos, tendo em vista a escassez e o tangível crescimento da produção de conhecimento associado ao tema.

Apesar destes resultados, escolhemos utilizar aqui o termo "empreendedorismo criativo", por 1) ser o termo descrito por Howkins (2012); 2) por ser esta a terminologia comumente adotada no mercado nacional; e 3) por tal terminologia fazer alusão ao "empreendedor cultural", atuante no ambiente da Indústria Cultural e posicionado na intersecção entre empreendedorismo, arte e economia (SWEDBERG, 2006).

Portanto, tomamos como empreendedorismo criativo a prática da criação de empreendimentos que tem como matéria prima a criatividade e o capital intelectual, baseado na construção e exploração de redes sociais, e cuja atuação se dá mediada por plataformas digitais. Objetivam criação e captura de valor a partir de oportunidades identificadas, tem à frente o empreendedor responsável pela organização/operação e por assumir os riscos associados, e cujos índices de sucesso podem estar aliados aos termos da economia clássica e/ou criativa. Esse empreendimento pode partir de conhecimentos prévios do empreendedor empreendedor artesão -, da identificação de oportunidade - empreendedor oportunista -, ou de 
ator identificado em qualquer posição no continuum entre os dois pontos. Porém, acreditamos haver maior identificação do empreendedor criativo com o padrão artesão deste continuum; em investigação anterior, durante a qual realizamos primeira aproximação empírica a campo, constatamos que os atores observados empreendem a partir de seus conhecimentos prévios e experiência técnica, como apontado em estudo-piloto (SILVEIRA-NUNES; MONTARDO, 2017).

\section{PLATAFORMAS DIGITAIS DE COMÉRCIO - E-COMMERCES}

A Tecnologia de Informação (TI) foi marcada como 'o futuro', poderosa ferramenta empresarial alteradora das bases de competitividade e estratégias empresariais, acarretando mudanças profundas na maneira como negócios são feitos e criando novas oportunidades empresariais (ALBERTIN, 1999). Uma dessas novas maneiras é o comércio eletrônico, reconhecido mundialmente como e-commerce (MOREIRA, 2016), "qualquer negócio transacionado eletronicamente, no qual estas transações ocorrem entre dois parceiros de negócio ou entre um negócio e seus clientes” (CAMERON apud ALBERTIN, 1999, p.49); e que usa TI na "mediação das relações entre consumidores e fornecedores" (BEAM; SEGEV apud DINIZ, 1999, p.72). Também, como "a compra e a venda de informações, produtos e serviços por meio de redes de computadores" (KALAKOTA; WHINSTON apud ALBERTIN, 1999, p.49); "o suporte para qualquer tipo de transações de negócio sobre uma infra-estrutura digital" (BLOCH; PIGNEUR; SEGEV apud ALBERTIN, 1999, p.49); e seus estudos "são fortemente focados em segurança, criptografia ${ }^{3}$, moedas e pagamentos eletrônicos" (CONNOLY apud ALBERTIN, 1999, p.49). Pode funcionar como instrumento de promoção, canal de vendas ou de atendimento ao cliente, e ainda "propicia o desenvolvimento de novos produtos e mesmo de novos modelos de negócio" (BLOCH; PIGNEUR; SEGEV apud DINIZ, 1999, p.73). É também considerado forma efetiva de estar presente em diversos mercados, além dos limites da presença física da empresa (ALBERTIN, 1999). Atualmente,

compreende todo o processo on-line de desenvolvimento, marketing, vendas, entrega, atendimento e pagamento de produtos e serviços transacionados em mercados globais interligados, com o apoio de uma rede mundial de parceiros (O'BRIEN; MARAKAS apud MOREIRA, 2016).

\footnotetext{
${ }^{3}$ Criptografia é um método de proteção e privacidade de dados. Trata-se de técnicas de codificação de informação seguindo padrões - chaves - sem as quais é virtualmente impossível sua decodificação (
} 
Este ambiente está composto por várias camadas, envolvendo a) políticas e regras públicas; b) políticas e padrões técnicos; c) infovia pública; d) aplicações e serviços genéricos; e e) aplicações de comércio eletrônico (ALBERTIN, 1999). Quanto aos aspectos do comércio eletrônico, Albertin (1999) aponta 1) relação com clientes; 2) privacidade e segurança; 3) sistemas eletrônicos de pagamento; 4) adoção; 5) aspectos de implementação; 6) comprometimento organizacional; 7) aspectos legais; e 8) competitividade. No que diz respeito ao escopo deste estudo, focamos nos aspectos 2) privacidade e segurança; 3) sistemas eletrônicos de pagamento; e 7) aspectos legais. Tal escolha vem de encontro aos três principais desafios para o comércio eletrônico apontador por Stair; Reynolds (2015): 1) lidar com preocupações dos clientes; 2) superar a falta de confiança do cliente; e 3) superar questões globais.

Quanto à segurança dos dados durante o processo de pagamento, Moreira (2016) aponta a importância do Protocolo Secure Sockets Layer (SSL) ${ }^{4}$, autenticação de comunicação que garante a criptografia, ou proteção, dos dados de ambos atores da conexão, funcionando em conjunto com certificados digitais para identificação do servidor. Quanto aos métodos de pagamento, Moreira (2016) lista 1) dinheiro eletrônico, valor computadorizado, armazenado e utilizado para pagamentos segurado por certificados digitais, sendo um desses sistemas o PayPal, no qual o usuário cadastra cartões de crédito, débito e contas bancárias através dos quais transfere dinheiro para o sistema; e 2) cartões de crédito e débito, que adotam o padrão de segurança PCI (Payment Card Industry) ${ }^{5}$, e cujo uso está sujeito a diversos sistemas de verificação de dados, que garantem a identidade do usuário pela verificação de dados cadastrados com as empresas de cartões. Adaptando-se ao mercado brasileiro, o sistema PagSeguro $^{6}$ (2017) disponibiliza também a transferência de fundos por boleto bancário ou transferência bancária.

As plataformas digitais de comércio eletrônico nada mais são do que sistemas que permitem criar, visualizar e gerenciar uma loja on-line onde o empreendedor expõe à venda seus produtos ou serviços. Em outras palavras, as plataformas são sistemas eletrônicos que funcionam como o estabelecimento de uma loja física, isto é, o conjunto de mercadorias, utensílios e todo o aparato necessário ao negócio, etc. (CURSO DE E-COMMERCE, 2016). Plataformas digitais de e-commerce podem ser cindidas em duas partes, a saber: o front end, a parte da página do negócio visível ao consumidor, ou seja, a interface por onde o cliente

\footnotetext{
${ }^{4}$ Protocolo de Camada Segura de Soquetes, tradução nossa.

${ }^{5}$ Indústria de Cartões de Pagamento, tradução nossa.

${ }^{6}$ Solução de comércio eletrônico para transações comerciais mediante pagamentos on-line, similar ao PayPal.
} 
navega e efetua a compra; e o back end, a parte não vista pelo consumidor, por onde o gerenciador do negócio administra a loja (CRUZ, 2014).

As plataformas de e-commerce podem ser divididas em três diferentes tipos: a) SaaS (Software as a Service ${ }^{7}$ ), plataformas mais utilizadas no mercado, providas por desenvolvedores e cuja manutenção depende do pagamento de uma mensalidade, mas podem também ser gratuitas; b) licenciamento, quando a plataforma é criada por um terceiro e dele o empreendedor adquire o código-fonte para modificá-la e adaptá-la às necessidades do seu negócio - o caso de plugins ${ }^{8}$ c) desenvolvimento interno, quando o próprio empreendedor ou alguém a mando dele cria a plataforma a ser usada para suportar o empreendimento (PASCOTTO, 2015). Nesse espaço funciona o negócio on-line, onde ocorre a troca de informações e, especialmente, a coleta de dados pessoais dos consumidores. Daí a importância de saber, além dos meios pelos quais se deve estruturar o negócio, como podem ser tratados os dados pessoais dos clientes, evitando ofensas à legislação correlate, o MCI.

\section{LIMITES DA COLETA DE DADOS ON-LINE}

A principal questão, em relação aos limites legais do empreendedorismo on-line, é: que dados o empreendedor criativo pode solicitar dos seus consumidores para operacionalizar as atividades-meio de seu negócio? E como deve realizar a guarda desses dados?

Em 2009, o Ministério da Justiça realizou consulta pública através da internet a fim de obter informações sobre a vontade da população: se queriam, ou não, que o uso da internet fosse regulado (ASSOCIAÇÃO SOFTWARE LIVRE, 2009). A partir disso, a Presidenta da República, em 2011, propôs o projeto de lei que deu origem ao Marco Civil da Internet (MCI), apelido dado à Lei $\mathrm{n}^{\mathrm{o}}$ 12.965, de 23 de abril de 2014. O MCI estabelece diretrizes legais para o Poder Público e para os usuários da web, tendo em vista alguns princípios fundamentais: a liberdade de expressão, a privacidade e a livre iniciativa. Há outros princípios, mas esses são, sem dúvida, os que tem maior impacto nas relações diárias firmadas na internet.

As discussões acerca da violação da privacidade dos usuários se tornaram recorrentes depois de 2013, quando Edward Snowden revelou segredos sobre espionagem de cidadãos estadunidenses e de estrangeiros pelo governo dos Estados Unidos (G1, 2013). O MCI proíbe

\footnotetext{
${ }^{7}$ Software Como Serviço, tradução nossa.

${ }^{8}$ Programa de computador que adiciona funções a programas maiores, destinado a funcionalidades específicas, não compreendidas pelo programa original.
} 
que os dados coletados por sites e aplicações invadam, indevidamente, a intimidade daquele que os fornece.

Mais detalhes sobre como o provedor deve se comportar em relação aos dados dos usuários estão estabelecidas no inciso VII, nas alíneas "a", "b" e "c" do inciso VIII e no inciso IX, todos do art. $7^{\circ}$ do Marco Civil ${ }^{9}$. É nesse contexto que se insere a preocupação dos empreendedores criativos em relação aos sites de e-commerce. Quais regras precisam atender para que o sucesso de seu negócio não seja interrompido por uma acusação de violação do dever de proteção dos dados alheios?

As empresas que se aproveitam da tecnologia para fazer negócios na internet envolvem-se também relações de consumo, ou seja, os contratos que firmam devem obedecer também ao Código de Defesa do Consumidor (CDC), além das regras do MCI. De acordo com o CDC, instituído pela Lei $n^{\circ} 8.078$ de 1990, o consumidor tem direito à informação sobre aquilo que deseja adquirir, conforme o inciso III do art. $6^{\mathbf{0 1 0}}$. Nesse caso, o MCI e CDC se complementam. Segundo Jesus e Milagre (2014, p.35)

ao tratar de direitos envolvendo a proteção da privacidade e custódia dos registros de conexão, acesso a aplicações e dados pessoais, o Marco civil estabelece uma série de direitos (art. $7^{\circ}$, incs. VII, VIII e IX), dentre eles a obrigação de os provedores manterem em seus contratos informações claras sobre como tratam tais dados.

Em qualquer relação que envolva a venda de um produto ou de um serviço, o fornecedor deve informar o consumidor sobre aquilo que ele está adquirindo e também sobre os serviços acessórios, que podem ser: endereço de entrega do objeto, e-mail do comprador e dados pessoais para efetuar cadastro no site de e-commerce, tais como nome completo, endereço, $\mathrm{CPF}$, etc. Mas e o empreendedor criativo, que informações ele pode exigir do consumidor?

De acordo com Silva Neto (2001, p.35), "hoje todos podem ter acesso a quaisquer informações. Os mais variados bancos de dados encontram-se disponíveis na rede. O direito à

\footnotetext{
${ }^{9}$ Art. $7^{\circ}$. O acesso à internet é essencial ao exercício da cidadania, e ao usuário são assegurados os seguintes direitos: VII - não fornecimento a terceiros de seus dados pessoais, inclusive registros de conexão, e de acesso a aplicações de internet, salvo mediante consentimento livre, expresso e informado ou nas hipóteses previstas em lei; VIII - informações claras e completas sobre coleta, uso, armazenamento, tratamento e proteção de seus dados pessoais, que somente poderão ser utilizados para finalidades que: a) justifiquem sua coleta; b) não sejam vedadas pela legislação; e c) estejam especificadas nos contratos de prestação de serviços ou em termos de uso de aplicações de internet; IX - consentimento expresso sobre coleta, uso, armazenamento e tratamento de dados pessoais, que deverá ocorrer de forma destacada das demais cláusulas contratuais.

${ }^{10}$ Art. $6^{\circ}$ São direitos básicos do consumidor: III - a informação adequada e clara sobre os diferentes produtos e serviços, com especificação correta de quantidade, características, composição, qualidade, tributos incidentes e preço, bem como sobre os riscos que apresentem.
} 
privacidade se dissolve". A internet é uma facilitadora da acumulação e também da evasão de dados, conforme Whitaker (1999, p.154),

A digitalização é como uma moeda universal que permite o fluxo dos dados. Também a organização das bases de dados responde a princípios específicos, as informações podem transladar-se facilmente de uma base de dados a outra, facilitando-se, assim, sua comercialização. ${ }^{11}$

Ainda segundo Whitaker (1999), os dados digitais são associados a outras informações que possibilitam a identificação de potenciais consumidores, logo, a internet e os dados armazenados digitalmente são uma rica fonte para alcançar esse objetivo. Daí o interesse de grandes corporações em investir na coleta de dados para posterior venda a empresas de seguro, instituições financeiras, lojas on-line, etc. Mas Bruno (2013, p.132) assevera que "este monitoramento de rastros pessoais não é restrito ao universo securitário, estatal e corporativo". De acordo com Bruno (2013) há serviços de vigilância oferecidos na internet, que envolvem a coleta de dados digitais e são aplicados em outras instâncias (família, traição, comportamento, entre outros). Por tudo isso, faz sentido a preocupação com os dados pessoais que são coletados pelos sites de $e$-commerce, inclusive.

Recentemente, o MCI foi regulamentado por outra norma, cujo propósito é esclarecer alguns tópicos a fim de afastar divergências e possíveis equívocos interpretativos. Trata-se do Decreto $\mathrm{n}^{\circ}$ 8.771, de 11 de maio de 2016, cujos incisos I e II do art. 14 trazem as definições de dado pessoal e de tratamento de dados pessoais ${ }^{12}$. Essa norma que regulamenta o MCI confere o significado de dado pessoal, que é: a informação pela qual seja possível identificar uma pessoa, seja ela física ou jurídica.

O MCI determina que o provedor deve manter o sigilo das informações que coleta dos usuários, bem como informar que está coletando determinados dados, indicando quais são e qual a finalidade da coleta. É verdade que há dispositivos da Lei $\mathrm{n}^{\circ} 12.965$ que tratam da obrigatoriedade que o provedor tem de armazenar certas informações, mas

[..] embora exista o dever de custódia dos registros de conexão e acesso a aplicações, deve-se destacar que a guarda e o fornecimento dos dados devem se dar de modo menos invasivo possível ao usuário, respeitando-se sua privacidade (dentro do possível) e sua imagem. (JESUS; MILAGRE, 2014, p.46).

\footnotetext{
11 Tradução nossa.

12 Art. 14. Para os fins do disposto neste Decreto, considera-se: I - dado pessoal - dado relacionado à pessoa natural identificada ou identificável, inclusive números identificativos, dados locacionais ou identificadores eletrônicos, quando estes estiverem relacionados a uma pessoa; e II - tratamento de dados pessoais - toda operação realizada com dados pessoais, como as que se referem a coleta, produção, recepção, classificação, utilização, acesso, reprodução, transmissão, distribuição, processamento, arquivamento, armazenamento, eliminação, avaliação ou controle da informação, modificação, comunicação, transferência, difusão ou extração.
} 
Pode-se resumir tudo isso nos seguintes tópicos: a) o empreendedor criativo deve informar ao consumidor que alguns de seus dados - apenas o suficiente para a conclusão do negócio - precisarão ser coletados; b) deve informar que dados coletará do usuário (consumidor); c) por fim, deve deixar claro por que os coletará. Note-se que após coletar os dados, exceto por expressa autorização do consumidor, o empreendedor criativo não pode compartilhá-los com terceiros.

É curioso o fato de que o MCI permite a coleta de dados, definindo o que é proibido ao coletar dados pessoais, porém não faz nenhuma alusão ao tempo pelo qual os dados podem ficar armazenados no banco de informações daquele que os coleta. Quanto aos registros de conexão e registros de acesso a site ou conteúdo, o MCI é explícito ao dizer os prazos pelos quais o provedor deve mantê-los sob sua guarda: 6 (seis) meses e 1 (um) ano, respectivamente. ${ }^{13}$ Porém o mesmo não ocorre em relação aos dados pessoais.

Ainda não há solução jurídica para esse impasse. Entretanto, é certo que os dados não devem ficar para sempre sob a guarda daquele que os coleta. A eternização da manutenção de informações pessoais em bancos de dados digitais é bastante criticável segundo MayerSchönberger (2011, p.5), que questiona: "nós desejamos um futuro em que não podemos ser esquecidos porque nossos dados pessoais não são esquecíveis?"14 Nesse sentido, o empreendedor criativo precisa se preocupar em armazenar os dados coletados somente até que a razão que ensejou a coleta tenha se exaurido. Do contrário, poderá infringir o MCI.

\section{METODOLOGIA E RESULTADOS}

Considerando a existência da presente pesquisa dentro do universo de pesquisa em curso a nível de mestrado, utilizamos dados coletados pela pesquisadora, como observadora participante introspectiva (WALLENDORF; BRUCKS, 1993). Para as autoras (1993), introspecção implica a existência de, no mínimo, um indivíduo fornecendo dados verbais sobre aspectos de sua experiência, sendo que estes estão disponíveis apenas a este individuo, não observável diretamente por outros. As autoras (1993) identificam, a partir de estudo

\footnotetext{
${ }^{13}$ Art. 13. Na provisão de conexão à internet, cabe ao administrador de sistema autônomo respectivo o dever de manter os registros de conexão, sob sigilo, em ambiente controlado e de segurança, pelo prazo de 1 (um) ano, nos termos do regulamento.

Art. 15. O provedor de aplicações de internet constituído na forma de pessoa jurídica e que exerça essa atividade de forma organizada, profissionalmente e com fins econômicos deverá manter os respectivos registros de acesso a aplicações de internet, sob sigilo, em ambiente controlado e de segurança, pelo prazo de 6 (seis) meses, nos termos do regulamento.

14 Tradução livre dos autores.
} 
bibliográfico da produção relacionada ao tema, cinco categorias de pesquisa introspectiva, diferenciadas pelo papel representado pelo indivíduo introspectivo. Este papel é determinado pelo nível de proximidade ou intimidade entre pesquisador e indivíduo introspectivo, o número de indivíduos introspectivos e sua função no estudo.

A pesquisadora, como empreendedora criativa atuante no universo estudado, configura-se tanto como pesquisadora quanto como indivíduo introspectivo (WALLENDORF; BRUCKS, 1993), o que a permite utilizar experiências subjetivas dos processos analisados para inferir a existência de quatro perfis de Empreendedor Criativo (EC) quanto ao uso de plataformas on-line para comércio de produtos (bens e serviços): p1) usa serviços de mensagem (ex.: WhatsApp); p2) usa perfis em SRS (ex.: Facebook); p3) usa plataformas de e-commerce (ex.: Elo $7^{15}$ ); e p4) usa sites auto-geridos (ex.: WooCommerce ${ }^{16}$ ). Pensando esses perfis e as plataformas utilizadas para comércio, inferimos também que a preocupação com privacidade de dados, a nível de plataforma, cabe aos participantes da conversa em p1, aos desenvolvedores das plataformas em p2 e p3, e ao EC gestor do site em p4. Tal hipótese baliza a construção do questionário.

No presente estudo foi realizado um levantamento por meio de questionário de adesão voluntária, disponível na internet. Esse questionário, formulado usando a ferramenta Google Forms $^{17}$, foi dividido em 8 (oito) seções, as quais, por sua vez, compunham-se de perguntas cujas respostas deviam ser objetivas, isto é, "sim" ou “não". O convite para adesão foi efetuado através de postagens em grupos sobre Empreendedorismo no Facebook, postagens em perfis pessoais dos pesquisadores e compartilhamentos de amigos desses. Durante o período em que o questionário esteve disponível, de 23 de novembro a 24 de dezembro de 2016, 27 (vinte e sete) voluntários o responderam. Importante apontar que, no formulário, as respostas foram acompanhadas de breves explicações sobre cada item - perguntas e respostas.

Na seção intitulada "Privacidade on-line", à pergunta "Conhece o Marco Civil" 55,6\% dos voluntários disse ter conhecimento dessa Lei (Figura 1). O objetivo do questionamento era saber especificamente se o respondente conhecia as implicações do Marco Civil sobre a prática de coleta de dados e legislação acerca do uso da internet em âmbito nacional. Isso significa que, passados dois anos de vigência da Lei que regulamenta o uso da internet, ainda

\footnotetext{
${ }^{15}$ Plataforma de compra e venda de artesanato.

${ }^{16}$ Plugin gratuito que permite a criação de lojas virtuais diretamente no CMS WordPress; funciona como um kit de ferramentas contendo os elementos mais comuns em $e$-commerce como carrinho de compras, gateways de pagamento, etc

${ }^{17}$ Ferramenta gratuita on-line que permite a criação e distribuição de formulários.
} 
há um número significativo de empreendedores que não conhece as implicações do MCI sobre seus negócios on-line. ${ }^{18}$

\section{Conhece o Marco Civil da Internet?}

\section{7 responses}

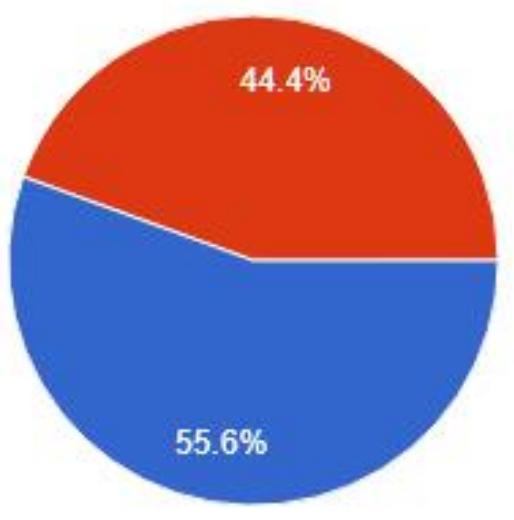

Figura 1: Gráfico das respostas à pergunta: “Conhece o Marco Civil da Internet?’ Fonte: Gerado pelo Google Forms, print screen dos autores, captura em 04 jul. 2017.

À segunda pergunta - Está ciente da importância de cuidados com privacidade de dados? -, cujo objetivo era compreender se os respondentes tinham conhecimento dos cuidados que deveriam ter durante a coleta de dados dos clientes - especialmente os dados relacionados ao pagamento - apenas 7,4\% deles disse não saber quais cuidados deveriam ter (Figura 2). As respostas a essas duas perguntas do questionário - presentes na seção "Privacidade on-line" do referido censo - permitem inferir o seguinte: embora o empreendedor on-line saiba da existência do Marco Civil, não conhece especificamente as regras que envolvem a proteção de dados pessoais dos potenciais consumidores, exceto quanto aos procedimentos de pagamentos via internet. Isso porque mais da metade dos respondentes da pesquisa afirma ter conhecimento sobre os cuidados que devem ter acerca dos processos de coleta e processamento de dados bancários de clientes através da rede mundial de computadores.

\footnotetext{
${ }^{18}$ Convém destacar que nessa pergunta a atenção foi direcionada ao gestor do empreendimento. Nesse caso, foram ignorados os membros da equipe desse empreendedor criativo apenas porque considerou-se a possibilidade de que um empreendimento pode ser executado por apenas um indivíduo, sem o auxílio de outros. Logo, há um número significativo de empreendedores criativos que, se atuarem sozinhos, estarão se submetendo aos riscos de desobedecer às diretrizes do MCI, pois não o conhecem.
} 


\section{Está ciente da importância de cuidados com privacidade de dados?}

\section{7 responses}

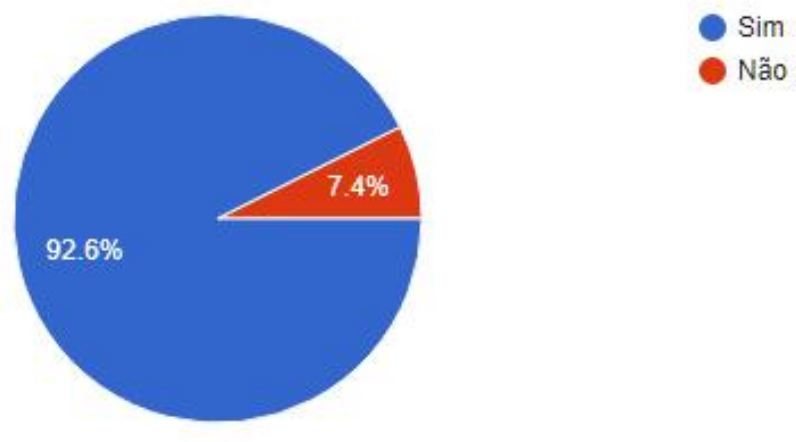

Figura 2: Gráfico das respostas à pergunta "Está ciente da importância de cuidados com privacidade de dados?"

Fonte: Print screen de gráfico gerado pelo Google Forms.

A terceira pergunta, "Seu empreendimento tem presença online?", foi adicionada como filtro, para garantir atuação comercial on-line de respondentes. Todos estes responderam afirmativamente (Figura 3). Um total de $24,1 \%$ dos voluntários respondeu utilizar site próprio, mas a maioria dos respondentes $(58,6 \%)$ diz usar sites de redes sociais para empreender. A minoria deles, ou seja, 17,9\% disse utilizar ambos.

\section{Seu empreendimento tem presença online?}

27 responses

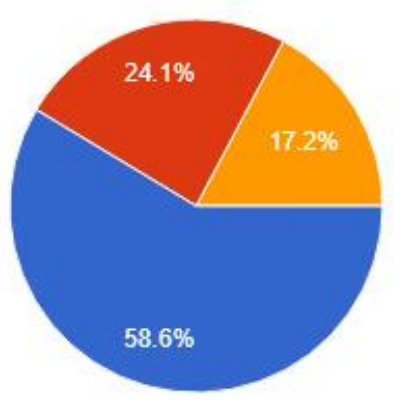

Sim, em Redes Sociais, Google, etc.

Sim, em site próprio, loja virtual, etc.

Sim, em todas as anteriores.

Não, não uso internet em meu empreendimento.

Figura 3: Gráfico das respostas à pergunta "Seu empreendimento tem presença online [sic]?". Fonte: Print screen de gráfico gerado pelo Google Forms.

Convém destacar as informações obtidas a partir da seção "Seu empreendimento online" do levantamento. A pergunta 4, "Quanto à atuação do seu empreendimento" (Figura 4) busca identificar o lugar de atuação do empreendimento, on-line, off-line ou ambos. A maioria 
dos respondentes, 70,4\%, diz atuar em ambos espaços, sendo que o montante de empreendedores que atua apenas em um ou outro espaço é o mesmo $(14,8 \%)$.

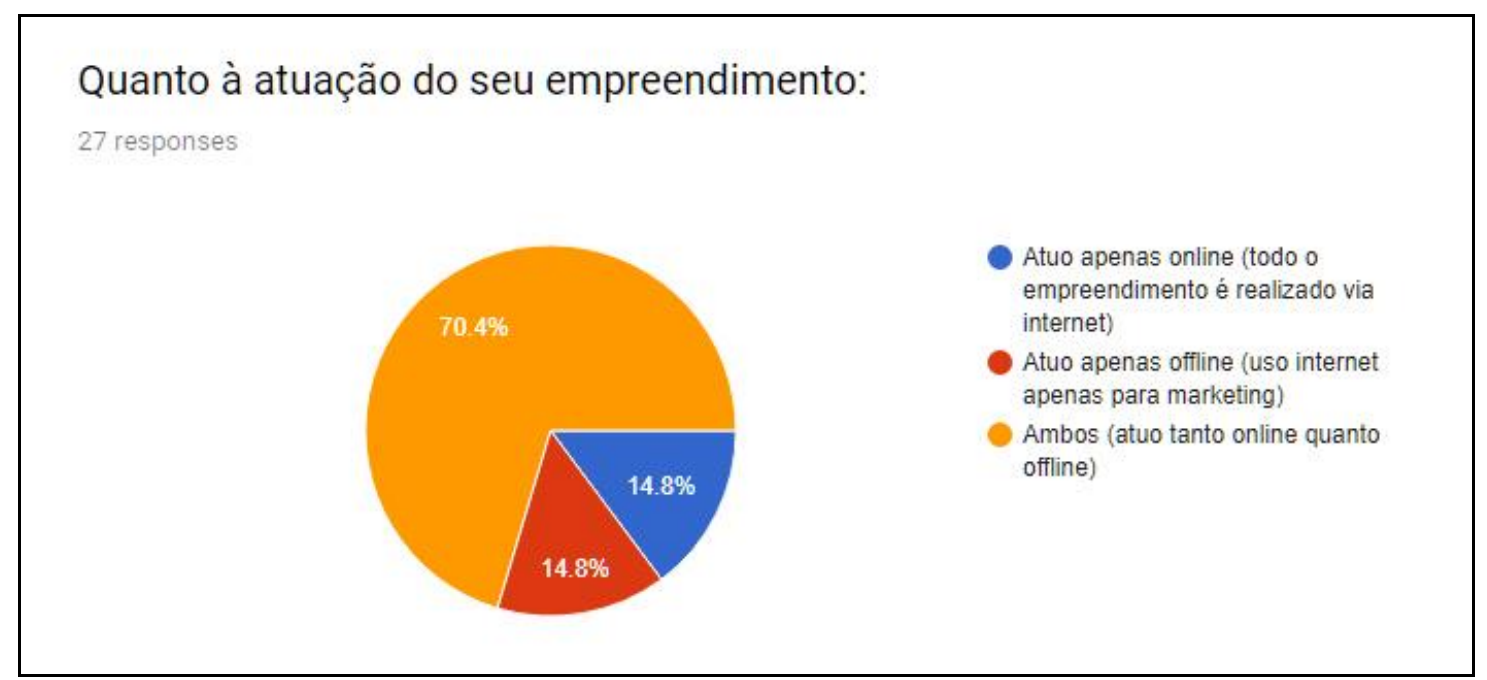

Figura 4: Gráfico das respostas ao questionamento "Quanto à atuação do seu empreendimento"

Fonte: Print screen de gráfico gerado pelo Google Forms.

Quando questionados sobre "De que maneira empreende on-line" (Figura 5), a maioria dos respondentes, representada por 92,6\%, disse utilizar sites de redes sociais para empreender. A questão, de múltipla escolha, mostra que 63\% dos respondentes também atuam via site próprio, marketplaces e lojas virtuais respondem por $11 \%$ cada, e e-commerces $7,4 \%$ das respostas. Sendo assim, a maior parte dos empreendedores criativos que atuam on-line estão submetidos também às regras de coleta de dados das políticas de privacidade próprias das plataformas digitais utilizadas.

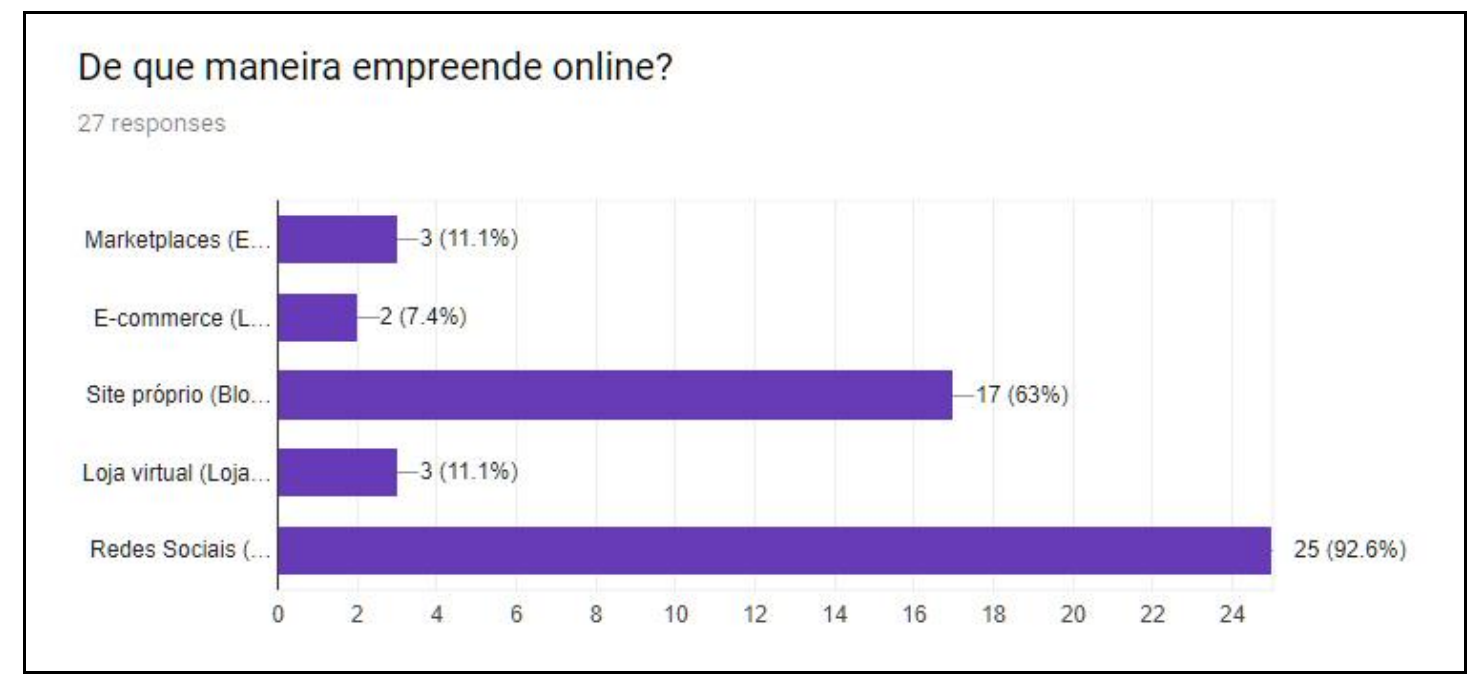

Figura 5: Gráfico das respostas à pergunta "De que maneira empreende online [sic]?". Fonte: Print screen de gráfico gerado pelo Google Forms. 
Foi questionado aos voluntários - seção "Coleta de dados" do levantamento - o seguinte: se realizavam a coleta de dados pessoais e dados bancários dos seus clientes. Quanto aos dados pessoais, informava-se aos voluntários que esse grupo abrangia a coleta das seguintes informações: nome, estado civil, profissão, endereço, e-mail, telefone, ou quaisquer outros que possam identificar uma pessoa (idade, gênero, orientação sexual, etc). Pouco mais da metade, 59,3\% dos respondentes afirmou efetuar a coleta de dados pessoais (Figura 6) e apenas 25,9\% dos voluntários disse coletar dados bancários (Figura 7). Isso indica que a coleta de dados bancários é reduzida, pois a maioria utiliza formas de pagamento on-line pelas quais há outro provedor de serviços que se encarrega da coleta e armazenamento dessas informações. É o que se depreende das respostas fornecidas nas seções "Pagamento digital" e "Sistemas de transferência de dinheiro".

Em seu site, realiza coleta de dados pessoais de seu cliente? 27 responses

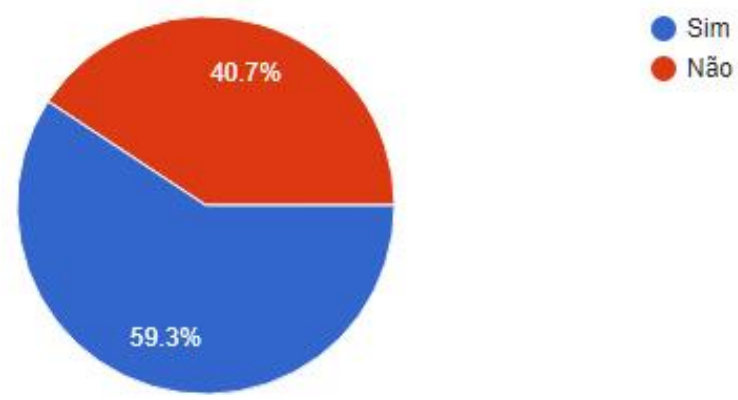

Figura 6: Gráfico das respostas à pergunta "Em seu site, realiza coleta de dados pessoais de seu cliente?"

Fonte: Print screen de gráfico gerado pelo Google Forms. 


\section{E quanto a dados bancários?}

27 responses

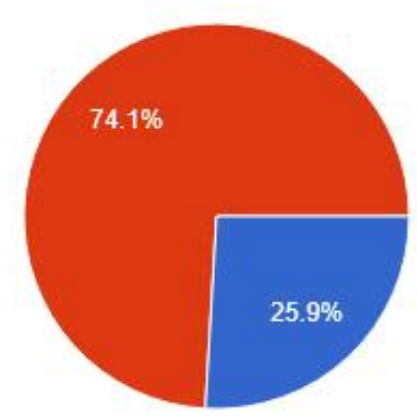

Figura 7: Gráfico das respostas ao questionamento "E quanto a dados bancários?". Fonte: Print screen de gráfico gerado pelo Google Forms.

Na seção "Pagamento digital", 59,3\% dos entrevistados afirmou não utilizar nenhuma forma de pagamento digital, enquanto 40,7\% disse utilizar algum meio de pagamento digital (Figura 8). Na seção "Sistemas de transferência de dinheiro" (Figura 9), dentre os entrevistados que afirmaram usar alguma forma de pagamento digital em seu empreendimento, 90,9\% disse utilizar sistemas on-line. Por isso a coleta de dados bancários feita diretamente pelo empreendedor não é tão expressiva.

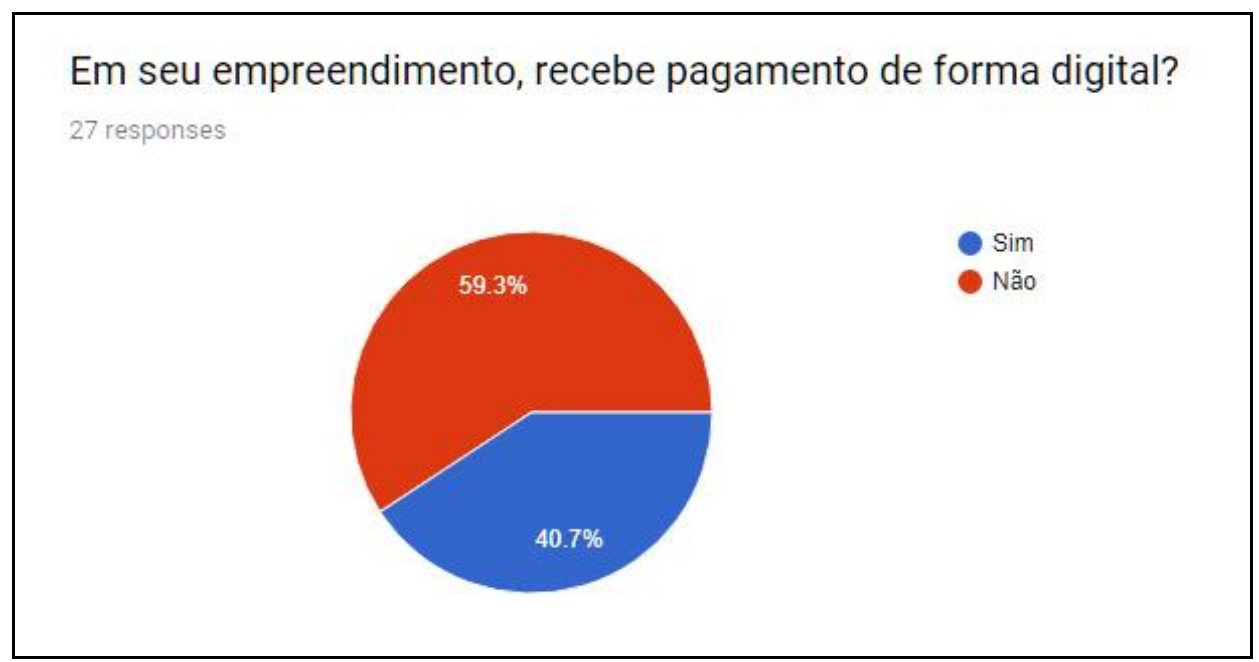

Figura 8: Gráfico das respostas à pergunta:

"Em seu empreendimento, recebe pagamento de forma digital?"

Fonte: Print screen de gráfico gerado pelo Google Forms. 


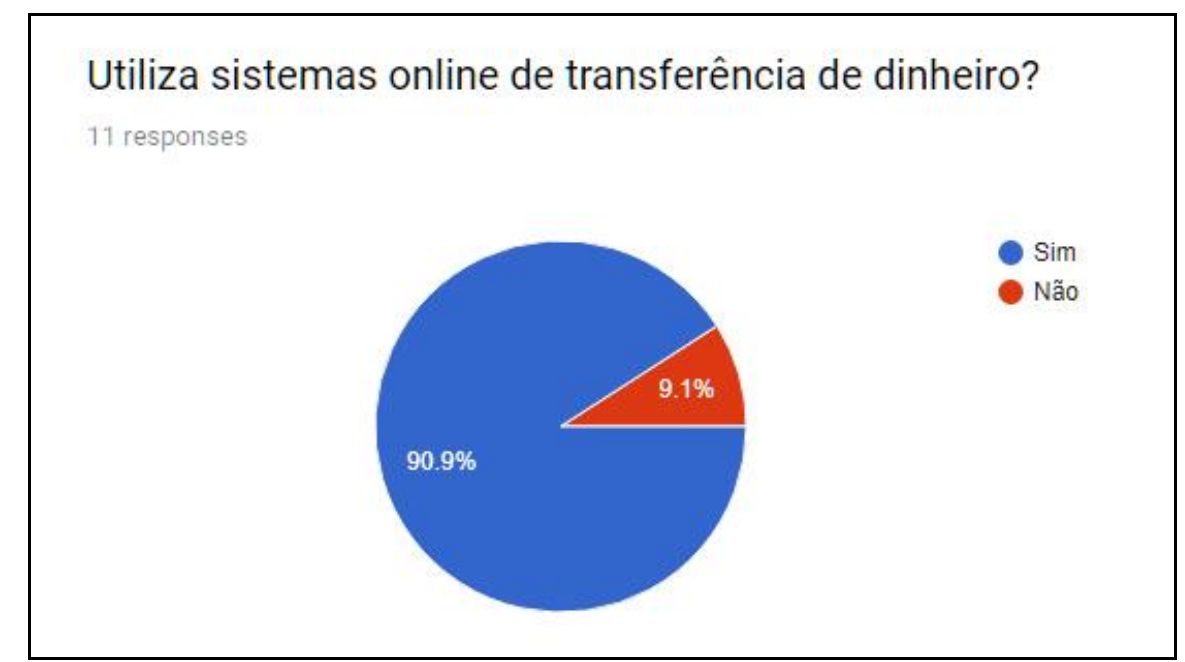

Figura 9: Gráfico das respostas à pergunta "Utiliza sistemas online [sic] de transferência de dinheiro?"

Fonte: Print screen de gráfico gerado pelo Google Forms.

$\mathrm{Na}$ seção "Segurança", foi questionado aos respondentes se disponibilizavam mensagens explicativas e/ou informativas sobre a coleta de dados dos clientes, dentre elas, mensagens de avisos de cookies, página sobre política de privacidade, certificados de segurança, etc. Pelas respostas à pergunta de múltipla escolha, concluiu-se que a maioria dos empreendedores criativos que atuam on-line não obedecem às diretrizes do MCI, embora a maioria deles $-55,6 \%$, de acordo com as respostas dos voluntários (Figura 1) - tenha afirmado conhecer a referida Lei. Essa conclusão se dá com base nas respostas de $50 \%$ dos voluntários (Figura 10) que afirmam não utilizar mensagens informativas e/ou explicativas sobre coleta de dados.

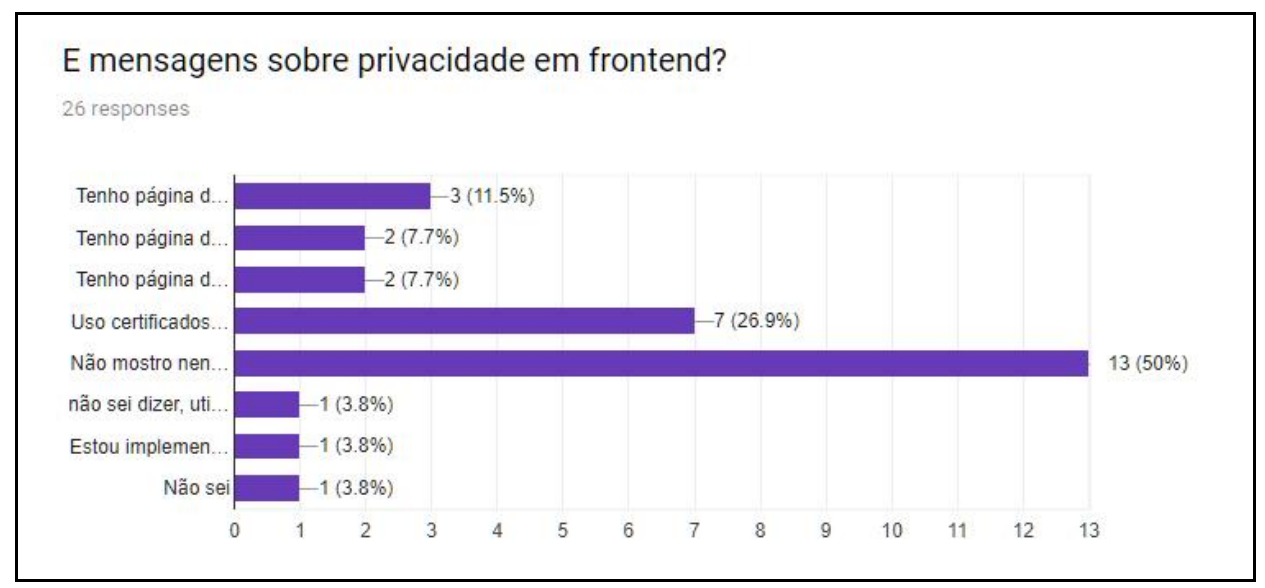

Figura 10: Gráfico das respostas à questão "E mensagens sobre privacidade em frontend [sic]?".

Fonte: Print screen de gráfico gerado pelo Google Forms. 
A partir destes resultados identifica-se um problema a ser discutido: o empreendedor criativo atuante on-line precisa conhecer mais detalhadamente o MCI, especialmente a parte em que a norma trata do dever de informar ao usuário sobre a coleta de dados. Isso porque, segundo o MCI e o CDC, o sujeito de quem se colhem os dados tem direito a dar seu consentimento expresso, sob pena de a coleta não ser válida. (OMMATI, 2014).

Em que pese a maioria dos respondentes afirme se preocupar com a segurança em relação aos dados dos clientes - apenas 18,5\% deles disse não tratar de questões de segurança em seus empreendimentos (Figura 11), conforme seção "Segurança" -; as respostas mostram que a prática não está adequada à sistemática do MCI. Segundo Lemos (2014), o MCI é importante por lidar com questões fundamentais que serão amplamente debatidas nas próximas décadas, mas especialmente por ser um texto voltado a garantir liberdades civis, dentre elas, o direito à privacidade.

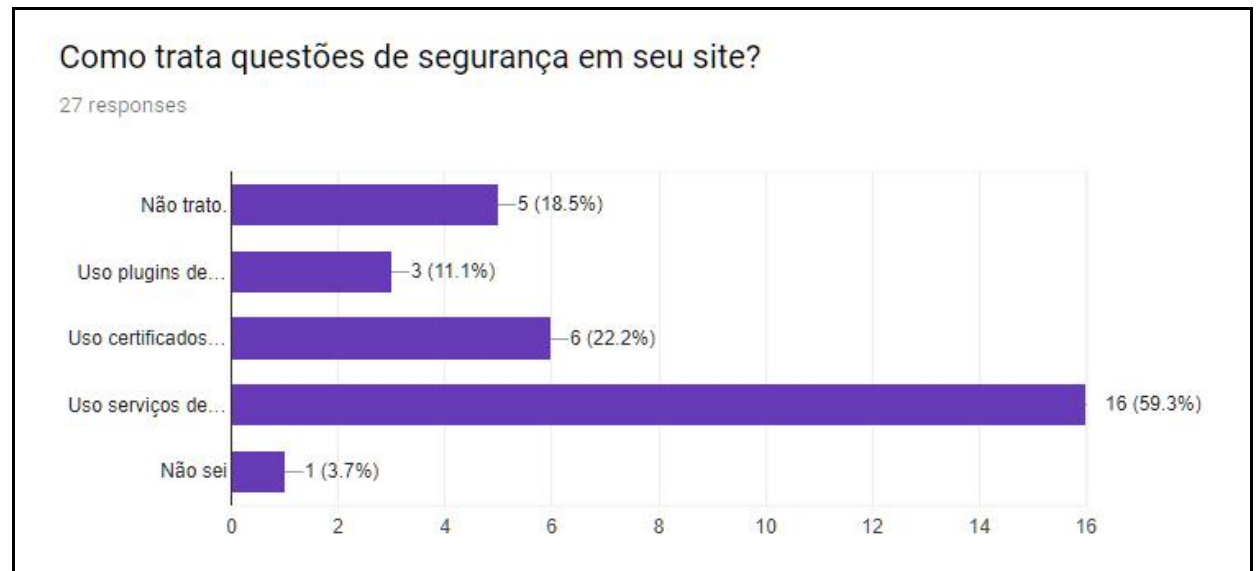

Figura 11: Gráfico das respostas à questão "Como trata questões de segurança em seu site?" Fonte: Print screen de gráfico gerado pelo Google Forms.

A partir desse levantamento, nota-se que não há uma adequação da atividade do empreendedor criativo que atua on-line às regras sobre a coleta de dados na internet. Trata-se de prática que viola o MCI e que tem potencial para se replicar e perpetuar, afinal, o aumento do número de empreendedores criativos que utilizarão a internet para exercer suas atividades pode crescer, mas isso não significa que atenderão ao MCI. Por isso, com base nesta pesquisa, pode-se afirmar que ainda há uma grande lacuna entre o que dispõe a Lei e o efetivo respeito aos direitos dos usuários por parte dos empreendedores criativos que atuam on-line. 


\section{CONSIDERAÇÕES}

De acordo com os dados, considerando aqueles que dizem conhecer o MCI, é baixo o número de empreendores criativos que aplicam todas as disposições legais no tocante à proteção do direito à privacidade dos consumidores. Portanto, há uma incongruência entre a quantidade de empreendedores que se dizem sabedores $d$ as regras sobre privacidade e coleta de dados e aqueles que verdadeiramente as obedecem. Diante destes resultados e considerando o MCI, observa-se que os empreendedores desrespeitam as regras jurídicas que tratam da coleta e armazenamento de dados, estando sujeitos a sanções legais.

Os dados mostram que mais da metade dos empreendedores criativos atuantes on-line afirma não prestar nenhuma informação ao consumidor sobre a coleta de dados que fazem. Como visto nas seções anteriores, o dever de informar o usuário de que seus dados estão sendo coletados é intangível, ou seja, o empreendedor não pode se furtar da obrigação de esclarecer ao cliente que: 1) coletará dados; 2) quais dados coletará; 3) por que razão os coletou.

Notou-se também durante a pesquisa que há muitos empreendedores criativos que não sabem exatamente os dados coletados por sites de redes sociais ou aplicações bancárias, quando seu empreendimento funciona em plataformas como o Facebook ou quando o pagamento se dá por meio on-line. Essas conclusões, formadas a partir dos dados levantados, permitem afirmar que, embora os empreendedores criativos digam conhecer as regras sobre a coleta de dados pessoais e a proteção da privacidade alheia, não observam integralmente o MCI.

Tal conclusão abre espaço para desenvolvimento de novos estudos, mais aprofundados, e que objetivem a construção de material educativo sobre os deveres e direitos do empreendedor criativo em sua atuação. Também, abre espaço para pesquisas sobre o futuro desenvolvimento do setor, que se prova cada vez mais forte na economia nacional.

\section{REFERÊNCIAS}

ALBERTIN, Alberto Luiz. Comércio eletrônico: um estudo no setor bancário. Rev.adm. contemp., Curitiba, v.3, n.1, p.47-70, 1999. Disponível em $<$ http://www.scielo.br/scielo.php?script=sci_arttext\&pid=S1415$65551999000100004 \& \operatorname{lng}=$ en\&nrm=iso >. Acessado jan. 2017. 
ASSOCIAÇÃO SOFTWARE LIVRE. Aberta a consulta pública para construção do marco civil da Internet. Software livre Brasil, 28 out. 2009. Disponível em:

$<\mathrm{http}$ ://softwarelivre.org/portal/noticias/aberta-a-consulta-publica-para-construcao-do-marco-civil-dainternet>. Acesso out. 2016.

BOURDIEU, P.A economia das trocas simbólicas. São Paulo: Perspectiva, 2007. (Coleção Estudos).

BIRLEY, S.; MUZYKA,D.F. Dominando os desafios do empreendedor. São Paulo: MakronBooks, 2001.

BRASIL. Código de Proteção e Defesa do Consumidor. Diário Oficial da União, Brasília, DF, 12 set. 1990.

BRASIL. Lei no 12.965, de 23 de abril de 2014. Diário Oficial da União, nº 77, Brasília, DF, 24 abr. 2014, Seção 1, p.1-3.

BRASIL. Decreto no 8.771, de 11 de maio de 2016. Diário Oficial da União, no 89-A, Brasília, DF, 11 mai. 2016, Edição Extra, p.7-9.

BRUNO, Fernanda. Máquinas de ver, modos de ser: vigilância, tecnologia e subjetividade. Porto Alegre: Sulina, 2013.

CÂMARA DOS DEPUTADOS. (Brasil). Projeto de Lei $\mathbf{n}^{\mathbf{0}}$ 1.755, de 29 mai. 2015. Disponível em: <http://www.camara.gov.br/proposicoesWeb/fichadetramitacao?id

Proposicao=1301180\&ord=1>. Acesso out 2016.

CÂMARA DOS DEPUTADOS. (Brasil). Projeto de Lei no 2.492, de 04 ago. 2015. Disponível em: $<$ http://www.camara.gov.br/proposicoesWeb/fichadetramitacao?id

Proposicao=1594826>. Acesso out 2016.

CASTELLS, Manuel. A Sociedade em Rede. São Paulo: Editora Paz e Terra, 2016.

CHASTON, Ian.Small creative industry firms: a development dilemma? Management Decision, v.46, n.6, p.819-831, 2008.

CREATIVE ENTREPRENEUS. Creative Entreprenerus - About. Creativeentrepreneurs.com. Disponível em: <http://creativeentrepreneurs.co/>. Acesso em: 2 jun.2017.

CRUZ, Anderson.Escolhendo a melhor plataforma de e-commerce. E-commerce Brasil, 17 jul. 2014. Disponível em: <https://www.ecommercebrasil.com.br/artigos/escolhendo-melhor-plataforma-de-ecommerce/>. Acesso jan.2017.

CURSO DE E-COMMERCE. O que é plataforma de e-commerce. 2016. Disponível em: <http://www.cursodeecommerce.com.br/o-que-e-plataforma-de-ecommerce/>. Acesso em 11 jan.2017.

DORNELAS, José; SPINELLI, Stephen; ADAMS, Robert. Criação de novos negócios: empreendedorismo para o século XXI. 2014.

DINIZ, E. H. Comércio eletrônico: fazendo negócios por meio da internet. Rev.adm. contemp., Curitiba, v.003, n.1, p.71-86, 1999. Disponível em $<$ http://www.scielo.br/scielo.php?script=sci_arttext\&pid=S1415$65551999000100005 \& \operatorname{lng}=$ en\&nrm=iso $>$. Acesso jan.2017. 
G1. Entenda o caso de Edward Snowden, que revelou espionagem dos EUA. 02 jul. 2013.

Disponível em: <http://g1.globo.com/mundo/noticia/2013/07/entenda-o-caso-de-edward-snowdenque-revelou-espionagem-dos-eua.html>. Acesso out. 2016.

EIKHOF, Doris Ruth; HAUNSCHILD, Axel. Lifestyle Meets Market: Bohemian Entrepreneurs in Creative Industries. Creativity and Innovation Management, v.15, n.3, p.234-241, 2006.

JESUS, D. de; MILAGRE, J. A. Marco Civil da Internet: comentários à Lei n.12.965/14. São Paulo: Saraiva, 2014.

LEMOS, Ronaldo. O Marco Civil como símbolo do desejo por inovação no Brasil. In: LEITE, George Salomão (coord.); LEMOS, Ronaldo. (coord.). Marco Civil da Internet. São Paulo: Atlas, 2014.

MAYER-SCHÖNBERGER. Delete: the virtue of forgetting in the digital age. New Jersey, United States of America: Princeton University Press, 2011.

MCCARTHY, Breda. Case study of an artists' retreat in Ireland: an exploration of its business model. Social Enterprise Journal, v.4, n.2, p.136-148, 2008.

MOREIRA, R. A. O comércio eletrônico, os métodos de pagamentos e os mecanismos de segurança. REFAS - Revista Fatec Zona Sul, vol.3, p.16-30, 2016.

OMMATI, José Emílio Medauar. Direito (fundamental) ao consentimento expresso sobre a coleta, uso, armazenamento e tratamento de dados pessoais, que deverá ocorrer de forma destacada das demais cláusulas contratuais. In: LEITE, George Salomão (coord.); LEMOS, Ronaldo. (coord.). Marco Civil da Internet. São Paulo: Atlas, 2014.

PAGSEGURO. Como adicionar fundos em minha conta PagSeguro? Disponível em <https://pagseguro.uol.com.br/atendimento/perguntas_frequentes/categoria/comocomprar/pagamento/como-adiciono-fundos-em-minha-conta-pagseguro.jhtml>. Acesso jan.2017.

PARKER, G. G.; VAN ALSTYNE, M.; CHOUDARY, S. P.Platform Revolution: How Networked Markets Are Transforming the Economy. New York: W. W. Norton \& Company, 2016.

PASCOTTO, Alan.Quais são os tipos de plataformas de e-commerce. Nextcommerce, 19 mar. 2015. Disponível em: < http://nextecommerce.com.br/quais-sao-os-tipos-de-plataformas-de-e-commerce/>. Acesso jan.2017.

PETERS, Mike et al. The importance of lifestyle entrepreneurship: A conceptual study of the tourism industry. Pasos, v.7, n.2, p.393-405, 2009.

PINHEIRO, Cristiano Max Pereira et al. Mapeamento de conhecimento na plataforma Scopus: um estudo sobre a indústria criativa. RDBCI: Revista Digital de Biblioteconomia e Ciência da Informação, v.13, n.2, p.329-342, 2015.

PROFISSIONAL DE E-COMMERCE.COM.BR. E-commerce fatura R\$ 9,75 bilhões. Disponível em < http://www.profissionaldeecommerce.com.br/e-commerce-fatura-r-975-bilhoes-primeirotrimestre-de-2016/>. Acesso jan.2017.

SILVA NETO, A. M. e. Privacidade na internet: um enfoque jurídico. Bauru/SP: EDIPRO, 2001.

SILVEIRA-NUNES, B.; MONTARDO, S. P.Empreendedorismo Criativo: estabelecendo campo de pesquisa para futuros estudos. In: FREITAS, E. C. DE; SARAIVA, J. A.; HAUBRICH, G. F. 
(Eds.).Diálogos Interdisciplinares: Cultura, Comunicação e Diversidade no Contexto Contemporâneo - 2a edição. Novo Hamburgo: Feevale, 2017. p.165-178.

SNOW, Georgia. Creative Entrepreneurs website launched to help arts start-ups. Thestage.co.uk. Disponível em: <https://www.thestage.co.uk/news/2016/creative-entrepreneurs-website-launched-tohelp-arts-start-ups/>. Acesso em: 2 jun.2017.

STAIR, R. M; REYNOLDS, G. W. Princípios de Sistemas de Informação. Tradução Noveritis do Brasil. 11. ed. São Paulo: Cengage Learning, 2015.

STATISTA.COM. B2C e-commerce sales worldwide. Disponível em <https://www.statista.com/statistics/261245/b2c-e-commerce-sales-worldwide/>. Acesso jan.2017.

SWEDBERG, R. The cultural entrepreneur and the creative industries: beginning in Viena. J Cult Econ, Vol.30, p.243-261, 2006.

TECHTUDO.COM. O que é criptografía? Disponível em < http://www.techtudo.com.br/artigos/noticia/2012/06/o-que-e-criptografia.html>. Acesso em jul.2017.

WALLENDORF, M.; BRUCKS, M. Introspection in Consumer Research: Implementation and Implications. Journal of Consumer Research, v.20, n.3, p.339, 1993.

WHITAKER, R. El fin de la privacidad: como la vigilancia total se está convirtiendo en realidad. Barcelona, España: Paidós, 1999.

Original recebido em: 17 de março de 2017

Aceito para publicação em: 02 de junho de 2017

Bibiana Silveira-Nunes

Mestranda em Indústria Criativa pela Universidade Feevale, Novo Hamburgo, RS. Especialista em Artes Visuais pela Faculdade SENAC, Porto Alegre, RS. Bacharel em Design pelo Centro Universitário Franciscano, Santa Maria, RS.

Leonardo Brunetti Macedo

Mestrando em Processos e Manifestações Culturais pela Universidade Feevale, Novo Hamburgo, RS. Bacharel em Direito pela universidade tal, cidade tal, RS.

Sandra Portella Montardo

Doutora em Comunicação Social pela PUC, Porto Alegre, RS. Professora no Mestrado em Indústria Criativa e no Programa de Pós-Graduação em Processos e Manifestações Culturais da Universidade Feevale, Novo Hamburgo, RS.

Esta obra está licenciada sob uma Licença Creative Commons. 